\title{
IMPACT OF ENTOMOPATHOGENIC BACTERIA BACILLUS THURINGIENSIS ENTOMOPATHOGENIC ON THE YIELD AND QUALITY OF APPLE FRUIT
}

\section{O. V. Sherstoboieva, O. A. Demidov, A. B. Kryzhanivskyi}

Every year in Ukraine harvest losses from phytophages, diseases and weeds are $30-50 \%$ of yield. Control over phytophages using chemicals for plant protection, which became popular in the second half of the twentieth century, led to saturation of the biosphere with substances toxic to humans, animals and useful fauna and flora. Chemical insecticides and their decomposition products, which are often more toxic than pesticides themselves, accumulate in plants treated and do not entirely eliminated from them until the harvest.

An alternative to the chemical method of plant protection is biomethod which has not yet widespread in our country. However, a world market of protective biopreparations is largely saturated and 90-95\% is represented by spore-crystalline complexes of $B$. thuringiensis.

Toxicity of biopreparations is determined by the presence of microorganisms and their metabolic products in them. Specificity of action of bacteria is complex, associated with the various metabolites, with protein spore formation in the form of crystals being the main among them. Crystal formation is a characteristic feature of B. thuringiensis and plays an important role in its pathogenicity. Once metabolites penetrate cell membrane of intestinal epithelial cells of insects, they form pores or ion channels. This leads to an influx of water to the cells, creates osmotic imbalance and provides cell death.

During treatment of plants with liquid culture of B. thuringiensis, spores and endotoxin crystals affect the physiological processes that occur in the cells of plant leaves, which can manifest in changing the quality of apple products and change in yield.

In connection with the above, the aim of our studies was to investigate the impact of treatment of apple plantations with liquid cultures of $B$. thuringiensis during protection against phytophages not only to preserve the harvest, but also on quality parameters of apple fruit.

Materials and methods. The study was conducted during 2013-2015 at the Institute of Agroecology and Environmental Management of the NAAS and National Botanic Garden n. a. M. M. Grishko of the NAS of Ukraine (NASU NBG).

The material for the studies included liquid preparations, which bio-agents presented with the new strains of entomopathogenic, toxin-producing bacteria Bacillus thuringiensis 0371, 0376, 0408 and 787 (hereinafter - Bt). The strains were isolated from victims of natural populations of insects in the Crimea AR by the staff of the Laboratory of Microbiological Method of Plant Protection of the Institute of Agriculture of the Crimea of 
the NAAS, who whom the authors express their gratitude. Strains are keptin the Collection of beneficial soil microorganisms of the Institute of Agricultural Microbiology and Agroindustrial Manufacture of the NAAS.

The strain Bt 787 synthesizes protein crystalline endotoxin specific to leaf-eating phytophages from the ranks of Coleoptera and Lepidoptera. Bt strains 0371, 0376, 0408, except for the synthesis of protein crystalline endotoxin produce non-specific heat resistant water-soluble exotoxin.

For the treatment of the variety Jonagold, liquid formulations of the investigated strains were used in industrial environments, of the trains recommended by the authors, at the rate of $20 \mathrm{dm}^{3} /$ ha bacterial suspension with a titer of B. thuringiensis spores in the working fluid about $0.1 \cdot 10^{9} \mathrm{CFU} / \mathrm{cm}^{3}$. Consumption of the working fluid was $1000 \mathrm{dm}^{3} / \mathrm{ha}$.

Each preparation was used for the treatment of 10 apple plants in triplicate. Chemical systemic insecticide Confidor extra, water granules, of contact and intestinal action (rate of using is $70 \mathrm{~g} / \mathrm{ha}$ at the consumption of working fluid $1000 \mathrm{dm}^{3} / \mathrm{ha}$ ) was used as a comparator. Trees treated with water were used as a control.

The content of sugars in the apple fruits was measured by areometer. To this end, edible part was removed from fresh fruits, weighed and crushed. Then crushed mass was filtered through a filter paper. The filtrate was carefully poured into a graduated cylinder and placed in an incubator with a temperature of $20^{\circ} \mathrm{C}$. After one hour, areometer was placed into the sample. Under stable position of areometer, which does not touch the walls of the cylinder, parameters of sample density were read from the scale of the instrument.

The total acidity was measured by volumetric method using titration. For this purpose, sample weight of plant material was transferred to a flask with distilled water and thoroughly shaken. Then 3-4 drops of 1\% phenolphthalein solution was placed with subsequent titration using $0.1 \mathrm{~N} \mathrm{NaOH}$ solution to the appearance of a pink colour that persists for 20-30 seconds.

The concentration of ascorbic acid in apple juice was measured by titrimetry, which is based on the extraction of ascorbic acid with metaphosphoric acid solution followed by titration with 2,6-dichlorodiphenyl indophenolate sodium solution to the appearance of a light pink colour that persists for $15-20$ seconds.

Therefore, the use of biocontrol of phytophages in the apple garden provided harvesting of fruits in an average of 12.68-18.05 t/ha. The highest yield was obtained under treatment of plants with preparations based on B. thuringiensis strains 0408 and 0376, representing an average of 18.05 and $17.29 \mathrm{t} /$ ha, respectively. The yield of apple in the conditions of chemical protection against phytophages averaged $17.38 \mathrm{t} / \mathrm{ha}$. Thus, under preservation of fruit harvest, the effectiveness of protection of biological and chemical insecticides was the same. 
Fruits of Jonagold apple variety have high taste properties, and studied biological insecticides based on strains of $B$. thuringiensis $0376,0408,787$ did not significantly affect the balance of sugars and organic acids in them. Only treatment of apples with strain of B. thuringiensis 0371 and Confidor extra changed sugar-acidic balance upward by 1.1 and 1.5 units from optimum. 